\title{
Feasibility of Minocycline and Doxycycline Use as Potential Vasculostatic Therapy for Brain Vascular Malformations: Pilot Study of Adverse Events and Tolerance
}

\author{
Tim Frenzel ${ }^{a}$ f Chanhung Z. Lee ${ }^{a}$ Helen Kim $^{a}$ Nancy J. Quinnine ${ }^{a}$ \\ Tomoki Hashimoto $^{a}$ Michael T. Lawton ${ }^{b}$ B. Joseph Guglielmo ${ }^{c}$ \\ Charles E. McCulloch ${ }^{d}$ William L. Young ${ }^{a, b, e}$ \\ ${ }^{a}$ Center for Cerebrovascular Research, Department of Anesthesia and Perioperative Care, \\ Departments of ${ }^{b}$ Neurological Surgery, ${ }^{C}$ Clinical Pharmacy, ${ }^{d}$ Epidemiology and Biostatistics, and \\ eNeurology, University of California, San Francisco, Calif., USA; ${ }^{f}$ Department of Anaesthesiology and \\ Intensive Care, University Hospital Münster, University of Münster, Münster, Germany
}

\author{
Key Words \\ Brain vascular malformations $\cdot$ Doxycycline $\cdot$ Minocycline $\cdot$ \\ Tolerability $\cdot$ Vasculostatic therapy
}

\begin{abstract}
Background: Tetracyclines may be useful in preventing pathological vascular remodeling, thus decreasing the risk of spontaneous hemorrhage from brain vascular malformations. Methods: Arteriovenous malformation (AVM) and intracranial aneurysm patients undergoing noninvasive management were treated with minocycline or doxycycline (200 $\mathrm{mg} /$ day) up to 2 years in a prospective open-label safety pilot trial. The primary outcome was to compare dose-limiting intolerance, defined as treatment-related dose reduction or withdrawal between the agents. Results: Twenty-six patients with AVMs $(n=12)$ or aneurysms $(n=14)$ were recruited. Adverse event rates were similar to other reported trials of these agents; 4 of 13 (31\%) minocycline and 3 of 13 (23\%) doxycycline patients had dose-limiting intolerance (hazard ratio $=3.1,95 \% \mathrm{Cl}=0.52-18.11$, log rank $\mathrm{p}=0.70$ ). Conclu-
\end{abstract}

T. Frenzel and C.Z. Lee contributed equally to this work.

\begin{tabular}{ll}
\hline KARGER & $\odot$ 2008 S. Karger AG, Basel \\
$\begin{array}{l}\text { Fax }+41613061234 \\
\begin{array}{l}\text { E-Mail karger@karger.ch } \\
\text { www.karger.com }\end{array}\end{array}$ & $\begin{array}{l}\text { Accessible online at: } \\
\text { www.karger.com/ced }\end{array}$
\end{tabular}

sions: It is feasible to propose a long-term trial to assess the potential benefit of tetracycline therapy to decrease hemorrhagic risk in brain vascular malformations.

Copyright $\odot 2008$ S. Karger AG, Basel

\section{Introduction}

Tetracycline class drugs are emerging as clinically applicable nonspecific MMP inhibitors that have the potential to enhance vascular stability, thus reducing the risk of spontaneous hemorrhage. They also possess neuroprotective properties. Settings investigated to date include cerebral ischemia [1], intracranial hemorrhage (ICH) [2, $3]$, neurodegenerative disorders $[4,5]$, traumatic brain injury [6], and atherosclerotic disease [7]. In clinical trials, tetracyclines decreased MMP in abdominal aortic aneurysms (AAA) and carotid plaques [7-9]. We have preliminary data that doxycycline can reduce MMP levels in brain AVM (BAVM) tissue [10]. Further, both AVMs [11] and intracranial aneurysms [12] display inflammation as part of their lesional phenotype. Tetracyclines appear to generally display anti-inflammatory properties, beyond their anti-MMP effects [13].

William L. Young, MD

University of California, San Francisco

Department of Anesthesia and Perioperative Care, 1001 Potrero Ave, Room 3C-38 San Francisco, CA 94110 (USA)

Tel. +1 415206 8906, Fax +1 415206 8907, E-Mail ccr@anesthesia.ucsf.edu 
Unlike cancer-related chemotherapy that aims to shrink abnormal tumor tissue as cytotoxic therapy [14], MMP inhibition is not necessarily intended to obliterate the brain vascular malformation. Rather, the concept would be to stabilize vascular tissue and thereby decrease the risk of spontaneous $\mathrm{ICH}$, i.e., a vasculostatic approach.

Although tetracyclines have been studied extensively, long-term studies are rare. Further, none of the studies have targeted patients with intracranial vascular diseases. We performed this phase I study to document the expected tolerance and adverse events in the same population, on whom phase II trials would be conducted. This study was designed to test the feasibility of using minocycline and doxycycline as potential long-term vasculostatic therapy for brain vascular malformations, and to estimate frequency and nature of adverse events that might be expected from a larger phase II or phase III trial effort. We hypothesized that there would be no difference in tolerability to minocycline and doxycycline treatment in patients with cerebrovascular diseases.

\section{Methods}

This was a prospective open-label safety pilot trial, using minocycline or doxycycline treatment for patients with BAVM or intracranial aneurysms for up to 2 years. The primary outcome was to estimate dose-limiting intolerance (DLI) in this patient cohort and compare DLI between the two agents; DLI was defined as treatment-related dose reduction or study withdrawal. The secondary outcome was to examine laboratory values indicative of potential tetracycline-related hemological, hepatical and renal toxicity. The Institutional Committee on Human Research approved the study protocol, and all patients gave written consent before enrollment. The study was registered with ClinicalTrials. gov (NCT00243893).

\section{Study Population}

Patients with untreated BAVMs or aneurysms were recruited at the University of California, San Francisco. Patients had elected not to undergo invasive therapy, usually as a result of being deemed untreatable by conventional means. Other inclusion criteria were patients aged 13 and older; BMI within $30 \%$ of normal; white blood cell (WBC) $>3,800 / \mathrm{mm}^{3}$, creatinine $\leq 2.0 \mathrm{mg} / \mathrm{dl}$ and alanin aminotransferase (ALT) $\leq 2$ times upper limit of normal. Exclusion criteria included patients with unstable medical illness, e.g., unstable angina or advanced cancer over the last 30 days; contraindications to tetracyclines, including allergy or other intolerance; prior tetracycline use within 2 months of baseline visit; history of systemic lupus erythmatosis or vestibular disease, except benign positional vertigo; history of noncompliance with treatment or other experimental protocols.

\section{Study Medication}

Patients received either oral doxycycline or minocycline (100 mg twice a day). This dose was based on prior clinical trials that demonstrated a significant reduction of plasma MMP-9 [9] and tissue MMP-9 in AAA patients [7, 9]. Our previous pilot experiments with AVM tissue showed similar effects [10]. Besides the study drug and the experimental procedures, there was no change in patient management.

\section{Follow-Up Assessment}

Follow-up was conducted through telephone contact (weekly in the first 3 months, monthly for the next 3 months, and quarterly thereafter), laboratory evaluations, and patient reports of suspected adverse events. Adverse events and intercurrent neurological events were monitored. Compliance was monitored by patient self-report, phone contacts and monthly assessment of pill counts by returned blister packages. Levels of creatinine and ALT, hemoglobin, platelets and WBC were measured at baseline, then 3 months, 6 months, and every 6 months thereafter.

\section{Management of Side Effects}

The general algorithm for treating side effects was a stepwise progression, based in part on the initial severity of the side effect: (a) counsel patient on preventative measures; if unsuccessful, then (b) temporarily interrupt medication for 1 week or reduce to once a day dosing. If (b) was successful, the patient resumed normal dosage. If not, (c) discussion took place with primary physician to either try dose reduction again or, as a last resort, consider withdrawal from trial.

Serious adverse events (SAEs) were defined according to the FDA MedWatch definition (death, life-threatening, hospitalization, disability, or required intervention to prevent permanent impairment or damage).

\section{Statistical Methods}

If a patient could not resume the protocol-specified dose after the temporary interruption or dose reduction, then this was counted as the endpoint, DLI. Comparison of the study drugs was analyzed using Kaplan-Meier survival curves with a log-rank test, and a Cox regression to adjust for patient's age, gender and disease type.

Differences in baseline group characteristics were evaluated using Mann-Whitney U test, and categorical variables were analyzed using two-sided Fisher's exact test. Differences in lab values between groups over time were tested using repeated measures with a general linear model. All reported values were mean $\pm S D$, unless stated otherwise. A two-sided p value $<0.05$ was considered statistically significant.

\section{Results}

\section{Overview and Baseline Characteristics of Patient Population}

Twenty-six untreated patients with BAVMs $(\mathrm{n}=12)$ or aneurysms $(n=14)$ were enrolled in the study (table 1$)$. To date, 10 patients have completed 2 years of treatment. The mean follow-up duration was $17.6 \pm 7.7$ months for 
Table 1. Patient demographics and clinical characteristics

\begin{tabular}{|c|c|c|c|c|c|c|}
\hline Treatment & Gender & Age, years & Disease & Location & Size, $\mathrm{mm}$ & $\begin{array}{l}\text { Spetzler- } \\
\text { Martin } \\
\text { grades }\end{array}$ \\
\hline \multirow[t]{13}{*}{ Minocycline } & female & 19 & \multirow[t]{7}{*}{ AVM } & occipital & 37 & 4 \\
\hline & female & 53 & & cortical subcortical, ventricular, frontal & 92 & 5 \\
\hline & female & 15 & & frontal & 118 & 5 \\
\hline & male & 27 & & frontal & 45 & 4 \\
\hline & male & 21 & & thalamic & 32 & 4 \\
\hline & male & 21 & & parasagital, parietal & 34 & 4 \\
\hline & male & 27 & & cortical, subcortical, frontal, parietal & 61 & 4 \\
\hline & female & 72 & \multirow{6}{*}{ aneurysm } & basilar & 27 & \multirow[t]{6}{*}{$\mathrm{n} / \mathrm{a}$} \\
\hline & male & 38 & & basilar & 20 & \\
\hline & male & 54 & & basilar & 18 & \\
\hline & male & 68 & & basilar & 10 & \\
\hline & male & 32 & & basilar & 5 & \\
\hline & male & 52 & & carotid & 5 & \\
\hline \multirow[t]{13}{*}{ Doxycycline } & female & 64 & \multirow[t]{5}{*}{ AVM } & posterior fossa, cerebellar hemisphere & 40 & 3 \\
\hline & female & 49 & & temporal, parietal, occipital & 45 & 3 \\
\hline & female & 22 & & basal ganglia & 35 & 4 \\
\hline & female & 31 & & parietal & 40 & 3 \\
\hline & male & 34 & & cortical, subcortical, frontal & 35 & 4 \\
\hline & female & 38 & \multirow[t]{8}{*}{ aneurysm } & carotid & 14 & \multirow[t]{8}{*}{$\mathrm{n} / \mathrm{a}$} \\
\hline & female & 15 & & carotid & 4 & \\
\hline & female & 56 & & carotid & 20 & \\
\hline & male & 40 & & carotid & 12 & \\
\hline & male & 70 & & basilar & 18 & \\
\hline & male & 49 & & carotid & 5 & \\
\hline & male & 61 & & basilar & 10 & \\
\hline & male & 78 & & basilar & 7 & \\
\hline
\end{tabular}

doxycycline and $18.7 \pm 7.2$ months for minocycline. No significant differences were found between the study groups regarding baseline clinical characteristics. Nine patients are still actively receiving drug with remaining study time ranging from 1 to 15 months.

\section{Adverse Events, Patient Retention and Compliance with Study Medications}

Treatment-related adverse events occurred in 13 of the 26 patients enrolled, resulting in 3 (11.5\%) dose reductions and 5 (19.2\%) withdrawals. Two of 3 patients with dose reduction tolerated the 100 -mg daily dose subsequently and finished the 2-year course, while 1 later withdrew from the study. In addition, 3 events were judged as not treatment related, including 2 SAEs (1 ICH leading to death after taking doxycycline for 22 months and $1 \mathrm{ICH}$ after taking minocycline for 18 months), and 1 dropout due to lack of desire to continue being in the study. Overall tolerability as indicated by DLI was $69 \%$ for minocycline and $77 \%$ for doxycycline. Kaplan-Meier survival analysis (fig. 1) showed no difference of DLI between treatment groups $(\log$ rank $\mathrm{p}=0.70)$, but DLI showed a trend that was greater in the minocycline group compared to doxycycline [HR $(95 \% \mathrm{CI})=3.06(0.52-18.11)$, $\mathrm{p}=0.217]$, after controlling for the effects of female gender $[\mathrm{HR}=13.4(1.4-129.4), \mathrm{p}=0.03]$, aneurysms [HR = $4.0(0.6-25.6), \mathrm{p}=0.15]$, and age $[\mathrm{HR}=0.99(0.95-1.03)$, $\mathrm{p}=0.61]$. As a sensitivity analysis, we included all events (composite of DLI, 2 hemorrhages and 1 dropout), and found similar results ( $\log$ rank $\mathrm{p}=0.49)$.

The most reported side effect was photosensitivity $(6 / 26 ; 23 \%)$, followed by vertigo $(3 / 26 ; 12 \%)$, yeast infec- 


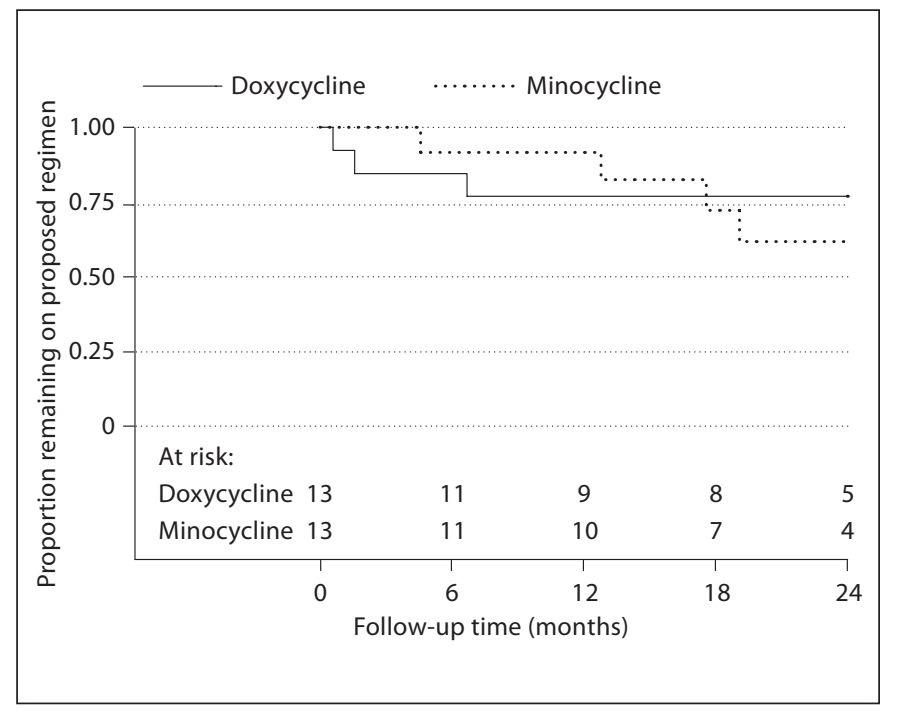

Fig. 1. Kaplan-Meier analysis of time from enrollment to dose reduction or withdrawal.

tion $(2 / 26 ; 8 \%)$, gastrointestinal symptoms $(2 / 26 ; 8 \%)$, hyperpigmentation $(1 / 26 ; 4 \%)$, and allergic reaction $(1 / 26$; $4 \%$; table 2). Most of the adverse events were mild and were managed according to the general algorithm. Specifically, photosensitivity and hyperpigmentation were managed by increased skin protection from exposure to ultraviolet light. Vertigo was managed by temporary interruption of the drugs. Yeast infection was treated with antifungal medications. Patients who developed gastrointestinal symptoms were recounseled to take the drugs with food and not to take them near bedtime. One patient who experienced an allergic reaction withdrew from the study. Yeast infection, vertigo and hyperpigmentation only occurred in the minocycline group, while the allergic reaction only occurred in the doxycycline group. The incidence of side effects was reported more frequently in the minocycline group (61\%) than in the doxycycline group (39\%), although the difference did not reach statistical significance with our sample size. The 2 incidences of SAEs, 1 hemorrhage each in AVM and aneurysm patients, rendered the annual bleeding rates for them to $5.6 \%(95 \% \mathrm{CI}=0.1-31.2 \%)$ and $5.8 \%(95 \% \mathrm{CI}=0.1-32.4 \%)$, respectively.

\section{Monitoring of Laboratory Values}

Since thrombocytopenia, azotemia and autoimmune hepatitis, although rare, could be potential side effects of tetracyclines, periodical laboratory values of hemologi- cal, hepatical and renal function were examined (table 3). While the WBC decreased over time in the minocycline group compared to the doxycycline $(\mathrm{p}<0.01)$, creatinine increased in the minocycline group compared to the doxycycline group $(\mathrm{p}=0.04)$. Hemoglobin $(\mathrm{p}=0.12)$, ALT $(\mathrm{p}=0.69)$ and platelets $(\mathrm{p}=0.45)$ showed no difference between the groups. The values for $\mathrm{WBC}$ and creatinine remained within the range of normal values and thus were considered not clinically significant.

\section{Discussion}

This study has shown a trend toward more frequent side effects and increased DLI from the minocycline treatment, although the difference between minocycline and doxycycline did not reach statistical significance in this small pilot study. There were no trends showing an increase in adverse events compared to other tetracycline clinical trials $[9,15]$.

The percentage of side effects observed in this study (50\%) was similar to, or even slightly lower than, previously reported clinical trials in other cardiovascular or neurological diseases. For instance, $61 \%$ of the subjects reported side effects in a multicenter study with 6 months of doxycycline at the same dosage in AAA patients [9]. The use of broad spectrum antibiotics for extended periods (1-2 years) to influence cardiovascular disease, e.g., through treatment of a potential chlamydial infection, has not revealed a significant issue with side effects regarding safety or compliance [16]. In recent trials examining the role of minocycline in neurodegenerative diseases, a futility trial in Parkinson's disease revealed 77\% tolerability and reported upper respiratory symptoms, joint pain and nausea as the most common side effects [15].

While the range of adverse events was similar in both drugs, side effects were less frequent in the doxycycline group. In our study population, the rate of gastrointestinal side effects was very low in both groups, in contrast to others showing that doxycycline was associated with a much higher risk of upper gastrointestinal disorders [17]. Vertigo, consistent with previous reports, occurred only in the minocycline group in our study. In contrast to reported hypersensitivity reactions to minocycline [18], we had only one case in the doxycycline group, and none in the minocycline group. Our monitoring of laboratory values did not reveal signs of thrombocytopenia, hepatal or renal dysfunction, although they have been documented as side effects by others [19]. None of our patients re- 
Table 2. Adverse events reported from individual patients

\begin{tabular}{|c|c|c|c|c|c|c|c|}
\hline & Patient No. & Yeast & GI & PS & $\mathrm{HP}$ & Vertigo & Allergy \\
\hline \multirow[t]{13}{*}{ Minocycline } & 1 & - & - & - & - & yes & - \\
\hline & 3 & - & - & - & - & - & - \\
\hline & 4 & - & - & - & - & - & - \\
\hline & 6 & - & - & yes & - & - & - \\
\hline & 7 & yes & - & - & - & - & - \\
\hline & 8 & - & - & - & - & - & - \\
\hline & 10 & - & - & yes & yes & - & - \\
\hline & 14 & - & yes & - & - & yes & - \\
\hline & 15 & yes & - & - & - & - & - \\
\hline & 16 & - & - & - & - & - & - \\
\hline & 18 & - & - & - & - & - & - \\
\hline & 19 & - & - & yes & - & - & - \\
\hline & 26 & - & - & - & - & yes & - \\
\hline \multirow[t]{13}{*}{ Doxycycline } & 2 & - & - & - & - & - & - \\
\hline & 5 & - & - & - & - & - & - \\
\hline & 9 & - & - & - & - & - & - \\
\hline & 11 & - & - & - & - & - & - \\
\hline & 12 & - & yes & - & - & - & - \\
\hline & 13 & - & - & - & - & - & - \\
\hline & 17 & - & - & - & - & - & yes \\
\hline & 20 & - & - & yes & - & - & - \\
\hline & 21 & - & - & - & - & - & - \\
\hline & 22 & - & - & yes & - & - & - \\
\hline & 23 & - & - & - & - & - & - \\
\hline & 24 & - & - & - & - & - & - \\
\hline & 25 & - & - & yes & - & - & - \\
\hline & Total & $2(15 \%)$ & $1(8 \%)$ & $3(23 \%)$ & $1(8 \%)$ & $3(23 \%)$ & - \\
\hline \multirow{2}{*}{ Doxycycline } & Total & - & $1(8 \%)$ & $3(23 \%)$ & - & - & $1(8 \%)$ \\
\hline & $\mathrm{p}$ & 0.48 & 1.00 & 1.00 & 1.00 & 0.22 & 1.00 \\
\hline
\end{tabular}

Table 3. Follow-up laboratory tests during the study

\begin{tabular}{llccccc}
\hline \multirow{2}{*}{ Laboratory tests } & \multirow{2}{*}{$\begin{array}{l}\text { Treatment } \\
\text { groups }\end{array}$} & \multicolumn{2}{l}{ Time points } & & & \\
\cline { 3 - 6 } & & 0 months & 3 months & 6 months & 12 months & 18 months \\
\hline WBC, $1,000 / \mu \mathrm{l}$ & minocycline & $5.7 \pm 1.3$ & $4.9 \pm 0.8$ & $5.4 \pm 1.1$ & $5.4 \pm 0.9$ & $5.2 \pm 1$ \\
& doxycycline & $6.7 \pm 2$ & $6.5 \pm 1.2$ & $6.7 \pm 2.3$ & $6.4 \pm 2$ & $6 \pm 0.7$ \\
Hemoglobin, g/dl & minocycline & $13.2 \pm 1.6$ & $13.7 \pm 1.5$ & $13.8 \pm 1.4$ & $13.6 \pm 1.4$ & $13.6 \pm 1.3$ \\
& doxycycline & $14 \pm 1$ & $14.4 \pm 0.9$ & $14.3 \pm 0.8$ & $14.5 \pm 1.1$ & $14.4 \pm 1$ \\
Platelet, $1,000 / \mu l$ & minocycline & $246 \pm 39$ & $237 \pm 49$ & $244 \pm 43$ & $249 \pm 52$ & $226 \pm 63$ \\
& doxycycline & $212 \pm 63$ & $230 \pm 59$ & $235 \pm 45$ & $229 \pm 62$ & $226 \pm 70$ \\
Creatinine, mg/dl & minocycline & $1.1 \pm 0.3$ & $1 \pm 0.2$ & $1 \pm 0.2$ & $1 \pm 0.2$ & $1 \pm 0.2$ \\
& doxycycline & $0.9 \pm 0.2$ & $0.9 \pm 0.2$ & $0.8 \pm 0.2$ & $0.9 \pm 0.3$ & $1 \pm 0.2$ \\
ALT, $\mathrm{U}$ & minocycline & $19 \pm 9$ & $19 \pm 6$ & $22 \pm 10$ & $21 \pm 7$ & $22 \pm 10$ \\
& doxycycline & $18 \pm 10$ & $20 \pm 1$ & $22 \pm 14$ & $24 \pm 17$ & $15 \pm 6$ \\
\hline
\end{tabular}


ported musculoskeletal toxicity, a common side effect in broad-band MMP inhibitors [20] or lupus-like syndrome, to minocycline [21, 22]. Although gender difference related to drug tolerability has not been reported in tetracyclines, our results suggested female gender as a possible predictor for increased intolerance. On the other hand, age did not seem to have an effect on DLI.

The two occurrences of hemorrhage in our study were not unexpected considering prior natural history studies. Increased age, initial hemorrhagic presentation, deep brain location, and exclusive deep venous drainage have been found as independent predictors of AVM hemorrhage in the untreated course after diagnosis $[23,24]$. Thus, the 82-year-old AVM patient with ICH in our study, who was at an advanced age and had a hemorrhagic presentation, could be at elevated risk. The ISUIA study found that aneurysm size and location are predictors of bleeding, with a first year rupture risk of $17 \%$ for giant aneurysms, reaching $50 \%$ at 5 years for posterior circulation lesions [25]. The aneurysm hemorrhage in our study occurred in a patient harboring a giant basilar tip aneurysm. Our point estimates of the observed hemorrhage rate were 5.6\%/year for AVMs and 5.8\%/year for aneurysms, both of which were well within those reported in previous studies.

We feel that this is an appropriate time to report the overall tolerability and feasibility of the study, since most of the side effect-related withdrawals experienced by the patients occurred within 18 months of the study. To date, the majority of our patients have been enrolled for more than 18 months, making this the longest reported followup of tetracycline treatment in neurological and vascular diseases compared to previous trials $[7-9,15]$. The retention of patients in this long-term study has been encouraging, as $69 \%$ have remained in the 2-year treatment course. Other shorter-term tetracycline clinical trials have reported higher retention rates, including $92 \%$ in the 6-month doxycycline treatment of AAAs [9], and 89\% in 12-month minocycline administration with Parkinson's disease. The length of the study appears to be a key factor, given 12 months as the mean time for all withdrawal events in our study. Allowing patients to take the highest tolerated dose, instead of fixed doses, may have reduced withdrawal rates.

This pilot study suggests that long-term tolerability of minocycline and doxycycline in patients with brain vascular malformations is sufficient to support a larger phase II or III trial to examine efficacy endpoints.

\section{Acknowledgments}

The following members of the UCSF AVM study project also contributed to this work: $\mathrm{S}$. Claiborne Johnston, $\mathrm{MD}, \mathrm{PhD}$; Nerissa Ko, MD; Vineeta Singh, MD; Wade Smith, MD, PhD; Michael McDermott, MD; Nalin Gupta, MD; Heather J. Fullerton, MD; David Saloner, PhD.

The authors would like to thank Trudy Poon for statistical analysis, Brad Dispensa and Philippe Jolivalt for database management, and Voltaire Gungab for editorial assistance. This work was supported in part by the following grants: NIH NS34949 (W.L.Y.), and AHA 0730360N (C.Z.L.).

\section{References}

1 Yrjanheikki J, Tikka T, Keinanen R, Goldsteins G, Chan PH, Koistinaho J: A tetracycline derivative, minocycline, reduces inflammation and protects against focal cerebral ischemia with a wide therapeutic window. Proc Natl Acad Sci USA 1999;96: 13496-13500.

-2 Sumii T, Lo EH: Involvement of matrix metalloproteinase in thrombolysis-associated hemorrhagic transformation after embolic focal ischemia in rats. Stroke 2002;33:831836.

-3 Power C, Henry S, Del Bigio MR, Larsen PH, Corbett D, Imai Y, Yong VW, Peeling J: Intracerebral hemorrhage induces macrophage activation and matrix metalloproteinases. Ann Neurol 2003;53:731-742.
4 Brundula V, Rewcastle NB, Metz LM, Bernard CC, Yong VW: Targeting leukocyte MMPs and transmigration: minocycline as a potential therapy for multiple sclerosis. Brain 2002;125:1297-1308.

5 Bonelli RM, Heuberger C, Reisecker F: Minocycline for Huntington's disease: an open label study. Neurology 2003;60:883-884.

-6 Sanchez-Mejia RO, Ona VO, Li M, Friedlander RM: Minocycline reduces traumatic brain injury-mediated caspase- 1 activation, tissue damage, and neurological dysfunction. Neurosurgery 2001;48:1393-1399.

7 Curci JA, Mao D, Bohner DG, Allen BT, Rubin BG, Reilly JM, Sicard GA, Thompson RW: Preoperative treatment with doxycycline reduces aortic wall expression and activation of matrix metalloproteinases in patients with abdominal aortic aneurysms. J Vasc Surg 2000;31:325-342.
-8 Axisa B, Loftus IM, Naylor AR, Goodall S, Jones L, Bell PR, Thompson MM: Prospective, randomized, double-blind trial investigating the effect of doxycycline on matrix metalloproteinase expression within atherosclerotic carotid plaques. Stroke 2002;33: 2858-2864.

-9 Baxter BT, Pearce WH, Waltke EA, Littooy FN, Hallett JW Jr, Kent KC, Upchurch GR Jr, Chaikof EL, Mills JL, Fleckten B, Longo GM, Lee JK, Thompson RW: Prolonged administration of doxycycline in patients with small asymptomatic abdominal aortic aneurysms: report of a prospective (phase II) multicenter study. J Vasc Surg 2002;36:1-12.

10 Hashimoto T, Matsumoto M, Li JF, Lawton MT, Young WL: Suppression of MMP-9 by doxycycline in brain arteriovenous malformations. BMC Neurol 2005;5:1. 
11 Chen Y, Fan Y, Poon KYT, Achrol AS, Lawton MT, Zhu Y, McCulloch CE, Hashimoto T, Lee C, Barbaro NM, Bollen AW, Yang G-Y, Young WL: MMP-9 expression is associated with leukocytic but not endothelial markers in brain arteriovenous malformations. Front Biosci 2006;11:3121-3128.

12 Chyatte D, Bruno G, Desai S, Todor DR: Inflammation and intracranial aneurysms. Neurosurgery 1999;45:1137-1146.

$\checkmark 13$ Weinberg JM: The anti-inflammatory effects of tetracyclines. Cutis 2005;75:6-11.

14 Kerbel R: Clinical translation of angiogenesis inhibitors. Nat Rev Cancer 2002;2:727739.

-15 NINDS-NET-PD: A randomized, doubleblind, futility clinical trial of creatine and minocycline in early Parkinson disease. Neurology 2006;66:664-671.

16 Grayston JT: Secondary prevention antibiotic treatment trials for coronary artery disease. Circulation 2000;102:1742-1743.
7 Jaspersen D: Drug-induced oesophageal disorders: pathogenesis, incidence, prevention and management. Drug Saf 2000;22:237249.

18 Smith K, Leyden JJ: Safety of doxycycline and minocycline: a systematic review. Clin Ther 2005;27:1329-1342.

19 Bocker R, Estler CJ, Ludewig-Sandig D: Evaluation of the hepatotoxic potential of minocycline. Antimicrob Agents Chemother 1991;35:1434-1436.

20 Scatena R: Prinomastat, a hydroxamatebased matrix metalloproteinase inhibitor. A novel pharmacological approach for tissue remodelling-related diseases. Expert Opin Investig Drugs 2000;9:2159-2165.

21 Elkayam O, Yaron M, Caspi D: Minocyclineinduced autoimmune syndromes: an overview. Semin Arthritis Rheum 1999;28:392397.
22 Sturkenboom MC, Meier CR, Jick H, Stricker BH: Minocycline and lupus-like syndrome in acne patients. Arch Intern Med 1999; 159:493-497.

23 Halim AX, Johnston SC, Singh V, McCulloch CE, Bennett JP, Achrol AS, Sidney S, Young WL: Longitudinal risk of intracranial hemorrhage in patients with arteriovenous malformation of the brain within a defined population. Stroke 2004;35:1697-1702.

24 Stapf C, Mast H, Sciacca RR, Choi JH, Khaw AV, Connolly ES, Pile-Spellman J, Mohr JP: Predictors of hemorrhage in patients with untreated brain arteriovenous malformation. Neurology 2006;66:1350-1355.

25 Wiebers DO, Whisnant JP, Huston J 3rd, Meissner I, Brown RD Jr, Piepgras DG, Forbes GS, Thielen K, Nichols D, O'Fallon WM, Peacock J, Jaeger L, Kassell NF, Kongable-Beckman GL, Torner JC: Unruptured intracranial aneurysms: natural history, clinical outcome, and risks of surgical and endovascular treatment. Lancet 2003;362: 103-110. 